\title{
Study of Proximate Composition, Quality Characteristics and Microbial Quality of Microwave Treated Liquid Whole Egg (LWE) Samples
}

\author{
N. Sumashree ${ }^{1 *}$, Sharanagouda Hiregoudar ${ }^{1}$, Udaykumar Nidoni $^{1}$, \\ K.T. Ramappa ${ }^{1}$ and Nagaraj Naik ${ }^{2}$ \\ ${ }^{1}$ Department of Processing and Food Engineering, College of Agricultural Engineering, \\ University of Agricultural Sciences, Raichur- 584 101, Karnataka, India \\ ${ }^{2}$ Department of Agricultural Microbiology, College of Agriculture, University of Agricultural \\ Sciences, Raichur- 584 101, Karnataka, India
}

Corresponding author

\begin{tabular}{|c|}
\hline Keywords \\
\hline $\begin{array}{l}\text { Microwave heating, } \\
\text { Pasteurization, } \\
\text { Quality parameters, } \\
\text { Exotic breed and } \\
\text { Indigenous breed }\end{array}$ \\
\hline Article Info \\
\hline $\begin{array}{l}\text { Accepted: } \\
\text { 04 August } 2019 \\
\text { Available Online: } \\
\text { 10 September } 2019\end{array}$ \\
\hline
\end{tabular}

A B S T R A C T

The present investigation was aimed to study the proximate composition, quality parameters, and microbial analysis of microwave heated egg liquid samples obtained from exotic (white leg horn) and indigenous breed eggs (aseel). The microwave heating was done by maintaining different time levels $(20,40$ and $60 \mathrm{~S})$. By analyzing the data obtained during study of proximate composition, it was found that, microwave heating at $40 \mathrm{~S}$ was the best condition to pasteurize the egg liquid samples for storage. The quality of microwave heated samples was determined by considering $\mathrm{pH}$ (7.21 and 6.88), Viscosity (11.61 and 13.05), $\alpha$ - amylase activity (13.63 and 14.39$)$ and colour ( $L^{*} 63.58$ and 61.83 , $a^{*} 9.70$ and $13.18, b^{*} 49.91$ and 74.48$)$ for exotic and indigenous breeds, the results confirmed that microwave heating at $40 \mathrm{~S}$ gives the good quality egg liquid. Microbial analysis including total plate count and salmonella detection confirmed that microwave treated samples were within the safer limits $(<103 \log \mathrm{cfu} / \mathrm{mL})$ for total plate count and found salmonella negative for all samples. It was concluded that, microwave heating was an efficient and most economical method to produce pasteurized egg liquid over the thermal treatments without any loss of quality characteristics.

\section{Introduction}

Egg has been consumed since ancient times as it is a rich source of protein and contains other high quality nutrients. Eggs are used as ingredients in foods for their unique functional properties (Uysal et al., 2017). Due to their rich nutritive value of their contents, eggs are potential hosts and carriers for pathogenic

\section{microbes like Salmonella enteritidis} (Sivaramakrishnan, 2010). As a result of varying egg production with changing climatic pattern and risk of salmonellosis which occurs through shell eggs, there is a wide scope for preservation of eggs for longer storage life which can be achieved by conversion of shell eggs to egg products. 
Egg products refer to eggs that are removed from their shells for processing into convenience form and to use as ingredient in commercial foodservice and home use $(\mathrm{Wu}$, 2014). In recent years, the food industry prefers eggs broken and converted into liquid egg products. In production of Liquid Egg Products (LEPs), pasteurization is the important process to eliminate pathogenic microorganisms from the product. Heat treatment is the most common pasteurization method which provides microbial safety and increase shelf life of egg products, but can have harmful effect on quality characteristics of final product, which results in commercially undesirable finished products (Denmat et al., 1999). Alternative pasteurization methods including ultrasonic wave treatment, high electric field pulses, high hydrostatic pressure, irradiation followed by heat and nisin, $\mathrm{pH}$ adjusted pasteurization, hydrogen peroxide treatment, high hydrostatic pressure and ultra pasteurization combined with aseptic packaging are explored to extend the shelf-life and minimize disadvantages of thermal processing of liquid egg products. It was reported that most of these methods focused on elimination of pathogens like Salmonella, Listeria and E. Coli and cause substantial changes in the structure of LEPs by causing coagulation and denaturation of proteins (Miller et al., 2010).

In response to these limitations, there is a need for combination of novel processing technologies and antimicrobials for shelf-life extension of LEPs. Keeping in view of these aspects, Microwave heating with addition of nisin was preferred for pasteurization over conventional heating for rapid volumetric heating with microwaves at range of 915 to $2450 \mathrm{MHz}$ frequency and overcomes slow heating as in conventional thermal processes. So that better product quality could be retained. Hence, the present investigation aimed to study the effect of microwave heating on proximate composition, quality characteristics and microbial quality of pasteurized egg liquid obtained from eggs of two chicken breeds i.e. White leg horns (Exotic breed) and Aseel (Indigenous breed).

\section{Materials and Methods}

The fresh ' $A$ ' grade quality eggs of Exotic (White leg horn, WLH) and Indigenous breed (Aseel) hens were procured from Sri Sai Poultry farm, Raichur (Karnataka).

\section{Preparation of egg liquid samples by using WLH and aseel eggs}

The eggs were washed in clean water to remove stains and surface contaminants and air dried under electric fans to remove any adhered moisture. Following washing, eggs were manually broken into sterile container and care was taken to avoid broken shell pieces which may damage the quality of egg liquid. The obtained liquid whole egg was homogenised at $2500 \mathrm{rpm}$ for $30 \mathrm{~s}$ (AkpinarBayizit, 2010). Nisin with the concentration of $6.25 \mathrm{mg} / \mathrm{L}$ (Miller et al., 2010) was added to egg liquid samples and again homogenization was carried out at same condition. Then, 300 $\mathrm{mL}$ of liquid whole egg was transferred into previously sterilized glass bottles and used for further studies.

\section{Microwave heating of egg liquid samples}

The microwave heating is a process was electromagnetic waves are used for destruction of pathogens. The frequency for microwaves ranges from $300 \mathrm{MHz}$ to 300 GHz. The standard frequency used in domestic microwaves is $2.45 \mathrm{GHz}$. The Convection microwave oven of $2450 \mathrm{mHz}$ frequency and $900 \mathrm{~W}$ power (Canumir et al., 2002) was used for pasteurization of egg liquid and it is depicted in Plate 1. The fresh egg liquid samples filled in glass bottles were treated with microwave energy at $900 \mathrm{~W}$ for a 
specified period of time such as 20, 40 and 60 $\mathrm{s}$, respectively. The treated samples were collected and stored for further analysis.

\section{Proximate composition}

The proximate composition such as moisture content, crude protein, crude fat, total ash and carbohydrates were determined by the methods as described in AOAC, 2005.

\section{Moisture content}

The moisture content of fresh, control and microwave treated egg liquid samples was determined by vacuum oven method (AOAC, 2005: 925.30). The moisture content of the sample was calculated by using the following formula;

Moisture content $(\%)=\frac{\mathrm{W} 2}{\mathrm{~W} 1} \times 100$

Where,

$\mathrm{W} 1=$ Initial weight of the sample, $\mathrm{g}$ W2 = Final weight of the sample, $g$

\section{Crude protein}

The protein content of egg liquid samples was estimated using Kjeltech instrument by Kjeldahl's method (AOAC 2005; 925.30). The per cent protein was computed on total nitrogen basis using the following equation.

Nitrogen, $\mathrm{N}(\%)=$

Volume of $0.1 \mathrm{~N}$ HCL $(\mathrm{mL}) \times 0.1 \times 14.007$

Weight of sample (g) '1000 $\times 100 \ldots(2)$

Per cent protein on total nitrogen basis $=\mathrm{N}$ $(\%) \times 6.25$

\section{Crude fat}

The fat content in egg liquid samples was estimated using Mojonnier extraction tube by Mojonnier method (AOAC 2005; 925.32). It was calculated by using the formula;

Fat $(\%)=\frac{\mathrm{m} 1}{\mathrm{~m} 0} \times 100$. ...(3)

Where, $\mathrm{m} 0=$ mass in $\mathrm{g}$, of the fat obtained after extraction and blank correction

$\mathrm{m} 1$ = mass in $\mathrm{g}$, of the test portion of egg product sample

\section{Total ash}

The total ash content of fresh and microwave heated egg liquid samples was determined by muffle furnace method (AOAC, 2005; 900.02). The percentage of ash was calculated by using the following expression;

$$
\text { Ash }=\frac{\text { Weight of ash }(\mathrm{g})}{\text { Weight of sample }(\mathrm{g})} \times 100 \ldots \text { (4) }
$$

\section{Carbohydrates}

The carbohydrates in egg liquid samples were determined by difference method (AkpinarBayizit et al., 2010).

Total carbohydrates $=100-($ Protein + Fat + Moisture content+ Ash) ...(5)

\section{Quality parameters}

The quality attributes viz, $\mathrm{pH}$, Viscosity, colour and $\alpha$-amylase activity were determined. The reading of $\mathrm{pH}$ was directly recorded by immersing the electrode into the sample data was obtained from $\mathrm{pH}$ meter. The viscosities of fresh and microwave heated samples were determined by using a modular compact rheometer as described by Severa et 
al., (2010). The $\alpha$-amylase activity will determine the efficiency of pasteurization process of fresh and pasteurized egg liquid and evaluated for all treatments. Fifteen grams of egg sample was incubated with $2 \mathrm{~mL}$ of starch solution and boiled at $44^{\circ} \mathrm{C}$ for $30 \mathrm{~min}$. After incubation, $5 \mathrm{~mL}$ of solution was pipetted into $5 \mathrm{~mL}$ of $15 \%$ tri-chloroacetic acid solution in a conical flask. Further, $15 \mathrm{~mL}$ of water are added mixed thoroughly and suspension was filtered. Subsequently, $10 \mathrm{~mL}$ of filtrate were pipetted into $2 \mathrm{~mL}$ of iodine solution contained in a test tube. A blue violet colour indicates that egg has been adequately pasteurized. The final starch concentration in the samples of pasteurized whole liquid egg was obtained by absorbance readings using UV-Visible spectrophotometer as described by Silva et al., 2017. Hunter's lab colourimeter was used for the measurement of colour changes in egg liquid during studies.

\section{Microbial analysis}

The microbial analysis in terms of total plate count and salmonella were determined for fresh and microwave heated samples for all the treatments (AOAC 2005; 927.40). Ten milliliter of liquid egg samples were weighed into $90 \mathrm{~mL}$ of sterilized distilled water and blended for $15 \mathrm{~min}$ at room temperature. From this, one $\mathrm{mL}$ of the sample solution was accurately pipetted using micropipette into a test tube containing $9 \mathrm{~mL}$ of sterile distilled water (10-1) and serially diluted until 10-2 dilution was reached. One $\mathrm{mL}$ of aliquots each from 10-2 dilutions was transferred to the sterile petri plates for the enumeration of microbial load. Plates were duplicated for each dilution. Approximately, $15-20 \mathrm{~mL}$ of molten and cooled total plate count agar medium for total plate count and MacConkey agar for salmonella detection were added into petri plates and the plates were rotated clockwise and anticlockwise directions on the flat surface to have a uniform distribution of colonies. After the solidification of agar, the plates were inverted and incubated at $30^{\circ} \mathrm{C}$ for 2 days for total plate count and $18 \mathrm{hrs}$ for salmonella species. Total plate counts and salmonella were determined on agar plates and enumerated after an incubation period and number of cfu/mL of sample were calculated by applying the following formula.

No. of colony forming units/mL of the sample is

Mean number of cfu 'Dilution factor

$\mathrm{cfu} / \mathrm{mL}=\frac{}{\text { Volume of sample } \quad \cdots(6)}$

\section{Statistical analysis}

Completely randomized design (CRD) was used to analyse the data. After proper analysis, data were accommodated in the tables for interpretation of results. The microsoft excel was used for analysis and interpretation.

\section{Results and Discussion}

\section{Proximate analysis}

The proximate composition of eggs obtained from two breeds was shown in Table 1. The moisture content of White leg horn eggs $(76.38 \%)$ was higher than that of aseel eggs $(72.50 \%)$. The variation of moisture content is due to increase of fat percentage in fresh aseel chicken eggs. Similar values of moisture content for white leg horns $(75.41 \%)$ and for fayoumi breed $(75.35 \%)$ were reported by Rehman et al., (2016). The crude protein $(12.70 \%)$, crude fat $(12.68 \%)$, total ash $(0.89 \%)$ and carbohydrates $(1.23 \%)$ of raw aseel eggs were significantly higher from the other treatments. Rehman et al., (2016) reported that this variation might be due to higher albumen and yolk weight in aseel eggs than in WLH during his comparative study on WLH and Fayoumi breed eggs. From the present investigation, it was found that there 
was a decrease in moisture content, protein and fat content in microwave heated samples with increased exposure time (20, 40 and 60 S) when compared with fresh and control samples. It was reported that, increase in temperature leads to denaturation of proteins and decrease in crude protein content of sample (Michalaski, 1999).

Plate.1 Microwave oven

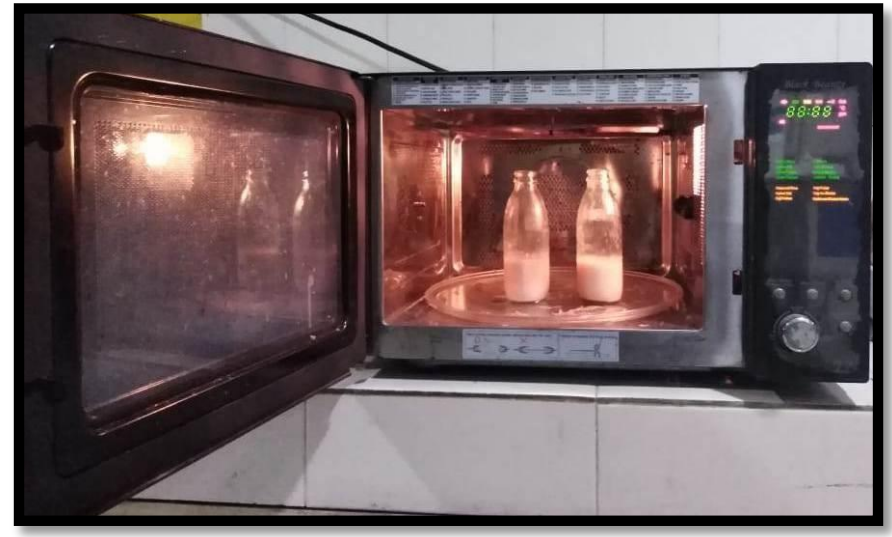

Table.1 Proximate composition of exotic and indigenous breed egg liquid samples

\begin{tabular}{|c|c|c|c|c|c|}
\hline Treatments & $\begin{array}{c}\text { Moisture } \\
\text { content }(\%)\end{array}$ & $\begin{array}{l}\text { Crude protein } \\
(\%)\end{array}$ & $\begin{array}{l}\text { Crude } \\
\text { fat }(\%)\end{array}$ & $\begin{array}{c}\text { Total ash } \\
(\%)\end{array}$ & $\begin{array}{c}\text { Carbohydrate } \\
\text { s (\%) }\end{array}$ \\
\hline Fresh $\left(\mathbf{B}_{1}\right)$ & 76.38 & 12.07 & 9.73 & 0.84 & 1.17 \\
\hline $\mathbf{B}_{1} \mathbf{T}_{\mathbf{0}}$ & 76.25 & 11.98 & 9.67 & 0.97 & 1.12 \\
\hline $\mathbf{B}_{1} \mathbf{T}_{1}$ & 76.13 & 11.95 & 9.66 & 1.13 & 1.10 \\
\hline $\mathbf{B}_{1} \mathbf{T}_{2}$ & 76.04 & 11.86 & 9.65 & 1.36 & 1.09 \\
\hline $\mathbf{B}_{1} \mathbf{T}_{3}$ & 75.42 & 11.21 & 9.64 & 2.73 & 1.08 \\
\hline $\operatorname{Fresh}\left(\mathbf{B}_{2}\right)$ & 72.50 & 12.70 & 12.68 & 0.89 & 1.23 \\
\hline $\mathbf{B}_{2} \mathbf{T}_{0}$ & 72.33 & 12.64 & 12.62 & 1.24 & 1.18 \\
\hline $\mathbf{B}_{2} \mathbf{T}_{1}$ & 72.00 & 12.62 & 12.59 & 1.64 & 1.16 \\
\hline $\mathbf{B}_{2} \mathbf{T}_{2}$ & 71.83 & 12.59 & 12.52 & 1.72 & 1.12 \\
\hline $\mathbf{B}_{2} \mathbf{T}_{3}$ & 71.77 & 12.53 & 12.47 & 2.13 & 1.10 \\
\hline Mean & 74.06 & 12.21 & 11.12 & 1.46 & 1.13 \\
\hline $\begin{array}{l}\text { Significanc } \\
\text { e }\end{array}$ & $* *$ & $* *$ & $* *$ & $* *$ & Ns \\
\hline S.Em \pm & 0.10 & 0.12 & 0.09 & 0.18 & 0.07 \\
\hline CD@1\% & 0.42 & 0.51 & 0.39 & 0.73 & 0.29 \\
\hline
\end{tabular}

Fresh (B1): Exotic breed egg liquid Fresh (B2): Indigenous breed egg liquid B1T0: Exotic breed + nisin (control) B2T0: Indigenous breed + nisin (control)

T1: Microwave oven at $20 \mathrm{~s}, \mathrm{~T} 2$ : Microwave oven at $40 \mathrm{~s}$ and T3: Microwave oven at $60 \mathrm{~s}$ ND: Not detected 
Table.2 Quality parameters of exotic and indigenous breed egg liquid samples

\begin{tabular}{|c|c|c|c|c|c|c|}
\hline \multirow[t]{2}{*}{ Treatment s } & \multirow{2}{*}{ pH } & \multirow{2}{*}{$\begin{array}{l}\text { Viscosit } \\
\text { y (cP) }\end{array}$} & \multirow{2}{*}{$\begin{array}{l}\alpha \text {-amylase } \\
\text { activity (\%) }\end{array}$} & \multicolumn{2}{|c|}{ Colour } & \multirow[b]{2}{*}{$b^{*}$} \\
\hline & & & & $L^{*}$ & $a^{*}$ & \\
\hline $\operatorname{Fresh}\left(\mathbf{B}_{1}\right)$ & 7.06 & 10.08 & 76.42 & 61.87 & 9.98 & 48.31 \\
\hline $\mathbf{B}_{1} \mathbf{T}_{0}$ & 7.32 & 11.31 & 75.82 & 62.85 & 9.85 & 49.64 \\
\hline $\mathbf{B}_{1} \mathbf{T}_{1}$ & 7.30 & 11.46 & 33.95 & 62.94 & 9.82 & 49.74 \\
\hline $\mathbf{B}_{1} \mathbf{T}_{2}$ & 7.21 & 11.61 & 13.63 & 63.58 & 9.70 & 49.91 \\
\hline $\mathbf{B}_{1} \mathbf{T}_{3}$ & 6.93 & 12.73 & 5.29 & 63.72 & 9.62 & 50.22 \\
\hline $\operatorname{Fresh}\left(\mathbf{B}_{2}\right)$ & 6.72 & 10.96 & 74.92 & 60.23 & 13.50 & 73.00 \\
\hline $\mathbf{B}_{2} \mathbf{T}_{\mathbf{0}}$ & 6.95 & 12.55 & 74.10 & 61.23 & 13.38 & $\mathbf{7 4 . 0 5}$ \\
\hline $\mathbf{B}_{2} \mathbf{T}_{1}$ & 6.92 & 12.84 & 33.30 & 61.53 & 13.28 & 74.22 \\
\hline $\mathbf{B}_{2} \mathbf{T}_{2}$ & 6.88 & 13.05 & 14.39 & 61.83 & 13.18 & 74.48 \\
\hline $\mathbf{B}_{2} \mathbf{T}_{3}$ & 6.82 & 13.36 & 5.10 & 62.17 & 13.05 & 74.72 \\
\hline Mean & 7.00 & 11.99 & 40.69 & 62.19 & 11.27 & 61.82 \\
\hline Significance & $* *$ & $* *$ & $* *$ & $* *$ & ** & $* *$ \\
\hline S.Em \pm & 0.09 & 0.09 & 0.10 & 0.08 & 0.11 & 0.10 \\
\hline CD @ 1\% & 0.37 & 0.38 & 0.44 & 0.34 & 0.47 & 0.42 \\
\hline
\end{tabular}

Fresh (B1): Exotic breed egg liquid Fresh (B2): Indigenous breed egg liquid B1T0: Exotic breed + nisin (control) B2T0: Indigenous breed + nisin (control)

T1: Microwave oven at $20 \mathrm{~s}, \mathrm{~T} 2$ : Microwave oven at $40 \mathrm{~s}$ and T3: Microwave oven at $60 \mathrm{~s}$ ND: Not detected

Table.3 Microbiological analysis of exotic and indigenous breed egg liquid samples

\begin{tabular}{|c|c|c|}
\hline Treatments & $\begin{array}{l}\text { Total plate count (log } \\
\text { cfu/mL) }\end{array}$ & Salmonella \\
\hline Fresh $\left(\mathbf{B}_{1}\right)$ & 2.56 & ND \\
\hline $\mathbf{B}_{1} \mathbf{T}_{\mathbf{0}}$ & 2.52 & ND \\
\hline $\mathbf{B}_{1} \mathbf{T}_{1}$ & 2.30 & ND \\
\hline $\mathbf{B}_{1} \mathbf{T}_{2}$ & 2.30 & ND \\
\hline $\mathbf{B}_{1} \mathbf{T}_{3}$ & 2.22 & ND \\
\hline $\operatorname{Fresh}\left(\mathbf{B}_{2}\right)$ & 2.60 & ND \\
\hline $\mathbf{B}_{2} \mathbf{T}_{\mathbf{0}}$ & 2.56 & ND \\
\hline $\mathbf{B}_{2} \mathbf{T}_{1}$ & 2.36 & ND \\
\hline $\mathbf{B}_{2} \mathbf{T}_{2}$ & 2.30 & ND \\
\hline $\mathbf{B}_{2} \mathbf{T}_{3}$ & 2.22 & ND \\
\hline Mean & 2.39 & ND \\
\hline $\begin{array}{l}\text { Significanc } \\
\text { e }\end{array}$ & $* *$ & \multirow{3}{*}{ NS } \\
\hline S.Em \pm & 0.10 & \\
\hline CD@1\% & 0.42 & \\
\hline
\end{tabular}

Fresh (B1): Exotic breed egg liquid Fresh (B2): Indigenous breed egg liquid B1T0: Exotic breed + nisin (control) B2T0: Indigenous breed + nisin (control)

T4: Microwave oven at 20 s, T5: Microwave oven at $40 \mathrm{~s}$ and T6: Microwave oven at $60 \mathrm{~s}$ ND: Not detected. 


\section{Quality parameters}

Data of quality parameters such as $\mathrm{pH}$, Viscosity, $\alpha$-amylase activity and colour are presented in Table 2. From the data recorded, it was found that $\mathrm{pH}$ of egg liquid was high for control samples (7.32 and 6.95) for exotic and indigenous breeds when compared to $\mathrm{pH}$ of the fresh and microwave treated samples, this might be due to addition of nisin which lead to no biochemical changes in samples. Whereas, further decrease in $\mathrm{pH}$ values of microwave treated samples was found with increasing time levels due to combined action of heat and nisin. The results obtained in present investigation are similar (7.74) with the findings of Atilgan and Unluturk (2008) in egg liquid. From the table, it was observed that the viscosity of microwave treated egg liquid was significantly high (12. 73 and 13.36) for exotic and indigenous breeds when compared to the viscosity of the fresh and control samples and it was noticed that there was increase in viscosity upon increasing time levels. This might be due to increase in solid content with increased heat treatment which leads to increase in viscosity of sample. Similar results for viscosity $(10.30 \mathrm{cP})$ were found by $\mathrm{Ma}$ et al., (1990). The $\alpha$-amylase activity of White leg horn eggs $(76.42 \%)$ was higher than that of aseel eggs $(74.92 \%)$. Whereas, further decrease in $\alpha$-amylase activity of microwave treated samples was found with increasing time levels due to action of heat. The results obtained in present investigation are similar with the findings of Silva et al., (2017) during evaluation of alpha- amylase activity as an indicator of pasteurization efficiency. From the data, it was observed that $L^{*}$ values of microwave treated egg liquid was significantly high (63. 72 and 63.17) for exotic and indigenous breeds when compared to the $L^{*}$ values of the fresh and control samples and it was noticed that there was increase in $L^{*}$ values upon increasing time levels. This might be due to increased heat treatment which leads to increase in lightness of sample. The $a^{*}$ values of egg liquid was high for fresh samples (9.98 and 13.50) for exotic and indigenous breeds when compared to control and microwave treated samples. Whereas, further decrease in $a^{*}$ values of microwave treated samples was found with increasing time levels due to combined action of heat and nisin. The $b^{*}$ values of microwave treated egg liquid was significantly high (50.22 and 74.72) for exotic and indigenous breeds when compared to the $b^{*}$ values of the fresh and control samples and it was noticed that there was increase in $b^{*}$ values upon increasing exposure time levels. Similar results for $L^{*}(65.00), \quad a^{*}$ (10.30), $\quad b^{*}$ (32.2) were obtained by Martinez and Maurer (1975).

\section{Microbial analysis}

The results of microbial analysis include total plate count $(\mathrm{cfu} / \mathrm{mL})$ and salmonella detection in fresh and pasteurized egg liquid samples of exotic and indigenous breed eggs are presented in Table 3. The total plate count of egg liquid was high for fresh samples $(2.56$ and $2.60 \mathrm{cfu} / \mathrm{mL})$ for exotic and indigenous breeds when compared to control and microwave treated samples. Whereas, further decrease in total plate count of microwave treated samples was found with increasing time levels due to combined action of heat and nisin. Similar results were found by Alvarez et al., (2012) for conventional cage eggs (2.34 log $\mathrm{cfu} / \mathrm{mL}$ ) and domestic eggs (3.59 log $\mathrm{cfu} / \mathrm{mL}$ ). Further, the presence of salmonella species was assessed and presented in Table 3. From the analysis it was found that there were no detectable salmonella species in fresh and pasteurized egg liquid samples of both exotic and indigenous breeds, respectively. All the analyzed samples showed salmonella negative. 


\section{References}

Akpinar, A., Ozcan, T., Ersan, Y. L. and Gurbuz, O., 2010, Impact of processing methods on nutritive value and fatty acid profile of hen eggs. Pakistan Veterinary Journal, 30(4): 219-222.

Alvarez, I., Niemira, B. A., Fan, X. and Sommers, C. H., 2007, Modeling the irradiation followed by heat inactivation of Salmonella inoculated in liquid whole egg. Journal of Food Science, 72(5):145-152.

AOAC, 2005, Official methods of analysis (16th Edition). Association of Official Analytical Chemists, Washington, DC

Atilgan, M. R. and Unluturk, S., 2008, Rheological properties of liquid egg products (LEPS). International Journal of Food Properties, 11(2):296-309.

Canumir, J. A., Celis, J. E., Bruijn, D. J. and Vidal, L. V., 2002, Pasteurisation of apple juice by using microwaves. Food Science and Technology, 35(5): 389392.

Ma, C.Y., Sahasrabudhe, M.R., Poste, L.M., Harwalkar, V.R., Chambers, J.R. and Hara,

K. P. J., 1990, Gamma irradiation of shell eggs. Internal and sensory quality, physicochemical characteristics, and functional properties. Canadian Institute of Food Science and Technology Journal, 23(4): 226-232.

Martinez, J. B. and Maurer, A. J., 1975, Quality preservation of liquid whole egg. Poultry Science, 54(5): 1395-1406.

Michalski, C. B., Brackett, R. E., Hung, Y. C. and Ezeike, G. O. I., 1999, Use of capillary tubes and plate heat exchanger to validate US Department of Agriculture pasteurization protocols for elimination of Salmonella enteritidis from liquid egg products. Journal of Food Protection, 62(2): 112-117.

Miller, P., Haveroen, M. E., Solichova, K., Merkl, R., Mcmullen, L. M., Mikova, K. and Chumchalova, J., 2010. Shelf-life extension of liquid whole eggs by heat and bacteriocin treatment. Czech Journal of Food Sciences, 28(4): 280289.

Rehman, S., Akhter, S., Khan, S. H. and Anjum, M. A., 2016, A comparative study on quality, proximate composition and cholesterol content of eggs and meat in Fayoumi and commercial white leg horn chickens. Cogent Food and Agriculture, 2(1): 1-7.

Severa, L., Nedomova, S. and Buchar, J., 2010, Influence of storing time and temperature on the viscosity of an egg yolk. Journal of Food Engineering, 96(2): 266-269.

Silva, G. R. D., Menezes, L. D. M., Lanza, I. P., Oliveira, D. D. D., Silva, C. A., Klein, R. W. T., Assis, D. C. S. D. and Cancado, S. D. V., 2017, Evaluation of the alpha-amylase activity as an indicator of pasteurization efficiency and microbiological quality of liquid whole eggs. Poultry Science, 96(9): 3375-3381.

Sivaramakrishnan, S. R., 2010, Microwave pasteurization of shell eggs, Ph.D Thesis, University of McGill, Canada, pp: 10-23.

Wu, J., 2014, Eggs and egg products processing. Food processing: Principles and Applications, 19(1): 437-455.

\section{How to cite this article:}

Sumashree, N., Sharanagouda Hiregoudar, Udaykumar Nidoni, K.T. Ramappa and Nagaraj Naik. 2019. Study of Proximate Composition, Quality Characteristics and Microbial Quality of Microwave Treated Liquid Whole Egg (LWE) Samples. Int.J.Curr.Microbiol.App.Sci. 8(09): 335-342. doi: https://doi.org/10.20546/ijcmas.2019.809.040 